\title{
PERFIL AGROSSOCIOECONÔMICO DE PRODUTORES RURAIS NA REGIÃO METROPOLITANA DO CARIRI CEARENSE
}

\author{
Agrossocioeconomic profile of rural producers in the Metropolitan Region of \\ Cariri Cearense
}

\author{
Anny Kariny Feitosa \\ Instituto Federal do Ceará - IFCE \\ anny.feitosa@ifce.edu.br \\ Carlos Wagner Oliveira \\ Universidade Federal do Cariri - UFCA \\ carlos.oliveira@ifce.edu.br
}

\section{Recebido em 15/07/2020 \\ Aceito em 13/11/2020}

RESUMO: Este artigo tem por objetivo diagnosticar o perfil agrossocioeconômico de produtores rurais na região Metropolitana do Cariri, por meio de um estudo de caso aplicado nos municípios de Crato, Juazeiro do Norte e Barbalha. Para tanto, realizou-se entrevista com sessenta agricultores, vinte de cada município, contendo perguntas a respeito da composição familiar; gênero, idade, estado civil, nível de escolaridade; exercício de outra atividade econômica além da agricultura; renda familiar; assistência técnica; tipo de cultivo; área total da propriedade e área cultivada; implementos agrícolas usados na propriedade; o destino da produção; dentre outros aspectos. Os resultados encontrados destacam a predominância do gênero masculino (61,7\%), com faixa etária de 46 a 65 anos (48,3\%), ensino fundamental $(46,6 \%)$, sendo $70 \%$ dos entrevistados entre não escolarizados e com nível fundamental, $76,7 \%$ entrevistados casados ou em união estável, com renda exclusiva da atividade agrícola de até 1 (um) salário-mínimo, atuando em pequenas propriedades, com área inferior a 5 (cinco) hectares. Dentre os produtos, destacam-se a avicultura, o cultivo de milho e feijão, com principal destino o consumo próprio familiar $(91,7 \%)$, sendo o excedente comercializado em feiras locais $(51,7 \%)$, entregues para os programas de alimentação escolar (30\%) e comercializado, em $25 \%$ dos casos, na sede da propriedade. Reforça-se a importância do fortalecimento do setor, por meio da criação de políticas governamentais de apoio e garantia da produção e comercialização na região.

Palavras-chave: Modelos agrícolas brasileiros; Sustentabilidade agroambiental; Meio ambiente.

ABSTRACT: This article aims to diagnose the agrosocioeconomic profile of rural producers in the Metropolitan Region of Cariri, through a case study applied in the municipalities of Crato, Juazeiro do Norte and Barbalha. To this end, an interview was conducted with sixty farmers, twenty from each municipality, containing questions about family composition; gender, age, marital status, education level; exercise of other economic activity besides agriculture; family income; technical assistance; cultivation type; total area of the property and cultivated area; agricultural implements used on the property; the destination of production; among other aspects. The results found highlight the predominance of the male gender $(61.7 \%)$, with the age group of 46 to 65 years $(48.3 \%)$, elementary school $(46.6 \%)$, with $70 \%$ of the interviewees among those without schooling and with fundamental level, $76.7 \%$ interviewees married or in a stable relationship, with exclusive income from agricultural activity of up to 1 (one) minimum wage, working in small properties, with an area of less than 5 (five) hectares. Among the products, poultry, corn and beans cultivation stand out, mainly family consumption (91.7\%), with the surplus sold at local fairs (51.7\%), delivered to school meals (30\%) and sold, in $25 \%$ of cases, at the property's headquarters. The importance of strengthening the sector is reinforced through the creation of government policies to support and guarantee production and marketing in the region. 
PERFIL AGROSSOCIOECONÔMICO DE PRODUTORES RURAIS NA REGIÃO METROPOLITANA DO CARIRI CEARENSE

Keywords: Brazilian agricultural models; Agri-environmental sustainability; Environment.

\section{INTRODUÇÃO}

A Região Metropolitana do Cariri cearense, atualmente, compõe-se pelos municípios: Juazeiro do Norte, Crato, Barbalha, Jardim, Missão Velha, Caririaçu, Farias Brito, Nova Olinda e Santana do Cariri, possuindo área total de $5.456,01 \mathrm{Km}^{2}$. Suas três cidades principais são Juazeiro do Norte, Crato e Barbalha, que mantêm vínculos territoriais e relacionais de complementaridade socioeconômica. A região destaca-se como a segunda mais expressiva do Estado (CEARÁ, 2020).

Dentre as atividades econômicas existentes, o setor de serviços é o mais representativo, seguido pela indústria. Não obstante, a participação do setor agropecuarista tem sido crescente na composição da riqueza gerada na região (IPECE, 2018). Pais (2014, p. 138) destaca a existência de "projetos e políticas públicas que destinaram recursos para ser investidos no campo, a fim de garantir uma qualidade de vida para os agricultores".

Considerando-se a relevância da atividade agropecuarista para a região, bem como reconhecendo-se que no Brasil existe uma grande heterogeneidade especialmente relacionada ao setor produtivo no meio rural (NUNES et al., 2015), justifica-se a necessidade de conhecer as características do perfil dos produtores rurais da Região Metropolitana do Cariri, suas particularidades econômicas e sociais.

Neste sentido, o diagnóstico agrossocioeconômico tem sido utilizado em diversos estudos (ARAUJO et. al., 2016; BATISTA, 2015; BRACHT; WERLANG, 2015; DATASEBRAE, 2018; MANGABEIRA et al., 2005; MIRANDA et al., 2007; RICHETTI et al., 2009) para identificar as características socieconômicas e produtivas de agricultores brasileiros. Diante do exposto, esta pesquisa tem como objetivo diagnosticar o perfil agrossocioeconômico de produtores rurais na região Metropolitana do Cariri cearense, por meio de um estudo de caso aplicado nos municípios de Crato, Juazeiro do Norte e Barbalha.

\section{MATERIAIS E MÉTODOS}

A presente pesquisa se desenvolveu na Região Metropolitana do Cariri (Figura 1), tendo como estratégia metodológica a realização de entrevista com 60 (sessenta) agricultores atuantes nos municípios de Crato, Juazeiro do Norte e Barbalha, em função de serem as principais cidades do aglomerado em análise. 
PERFIL AGROSSOCIOECONÔMICO DE PRODUTORES RURAIS NA REGIÃO METROPOLITANA DO CARIRI CEARENSE

\section{$2)^{2}$ REVISTA GEONORTE}

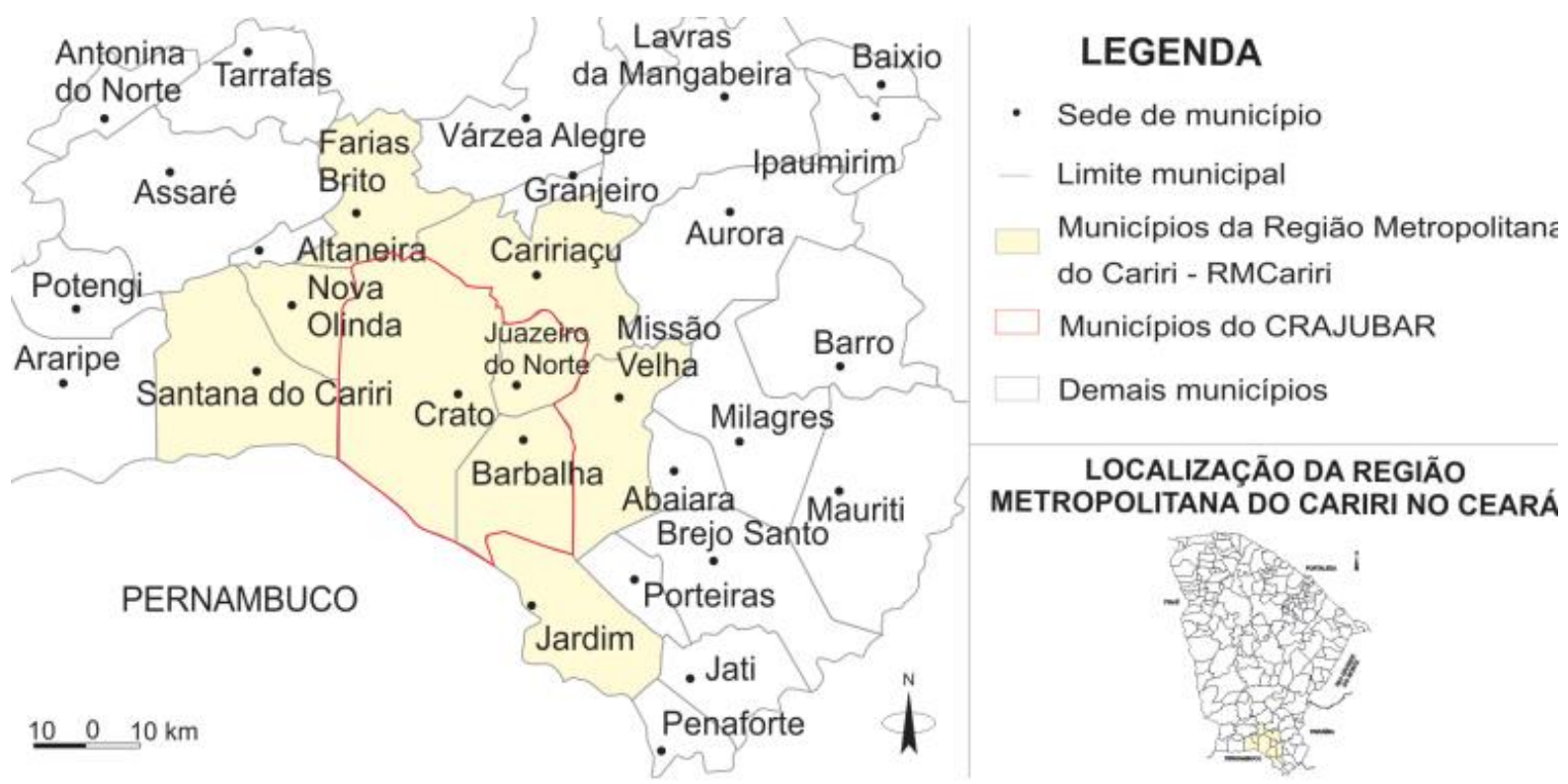

Figura 1. Região Metropolitana do Cariri. Fonte: Queiroz (2014)

Os municípios de Crato, Juazeiro do Norte e Barbalha possuem, respectivamente, área de 1.176,5 km², 248,8 km² e 569,5 km²; população de 121.428 hab., 249.939 hab. e 55.323 habitantes, dos quais $16,89 \%, 3,93 \%$ e $31,27 \%$ eram residentes na zona rural dos referidos municípios; e densidade demográfica de 104,87 hab/ $\mathrm{km}^{2}$, $1.006,91 \mathrm{hab} / \mathrm{km}^{2}$ e $92,31 \mathrm{hab} / \mathrm{km}^{2}$. O Índice de Desenvolvimento Humano (IDH) dos municípios em questão, em 2010, correspondiam a: Crato, 0,713; Juazeiro do Norte, 0,694; e, Barbalha, 0,683; enquanto o Índice de Desenvolvimento Municipal (IDM), de 2016, foi de 35,93; 35,20; e 47,32. Os Produtos Internos Brutos (PIBs Percapita), em 2015, eram de $R \$ 11.032,00 ; R \$ 14.742,00$; e $R \$ 12.005,00$ (IPECE, 2017).

As entrevistas foram realizadas durante o mês de outubro de 2019 e o instrumento utilizado continha perguntas a respeito: da composição familiar; gênero, idade, estado civil, nível de escolaridade dos agricultores; renda familiar; assistência técnica; tipo de cultivo; área total da propriedade e área cultivada; implementos agrícolas usados na propriedade; o destino da produção; dentre outros aspectos.

Os produtores foram selecionados mediante contato prévio com o Sindicato de Trabalhadores Rurais de Crato, a Feira de Produtores da Agricultura Familiar - Fepap, Cooperativa dos Agricultores e Empreendedores Familiares Rurais do Cariri COOPAEFAR, Associação de Produtores do Sítio Sabiá, Grupo da Economia Solidária e Turismo Rural da Agricultura Familiar de Barbalha e a Associação de Produtores do Sítio Boa Esperança. Obteve-se respostas dos produtores disponíveis e dispostos a participar. Como método de análise dos dados coletados, utilizou-se a análise de discurso (BARDIN, 2011).

Ressalta-se que a pesquisa obedeceu à Resolução 510/2016 do Conselho Nacional de Saúde, que faz referência às diretrizes e normas regulamentadoras de pesquisas/estudos em Ciências Humanas e Sociais. Além disso, o estudo possui 
PERFIL AGROSSOCIOECONÔMICO DE PRODUTORES RURAIS NA REGIÃO METROPOLITANA DO CARIRI CEARENSE

aprovação do Comitê de Ética em Pesquisa com Seres Humanos da UFCA (Universidade Federal do Cariri), com número CAAE 21048919.6.0000.5698.

\section{RESULTADOS E DISCUSSÕES}

Com base nas entrevistas realizadas, pode-se afirmar que, dentre o total de produtores, 38,3\% são do gênero feminino e $61,70 \%$ do gênero masculino (Figura 2). Especificamente do município de Juazeiro do Norte, observa-se que o gênero predominante é o masculino, com $70 \%$ dos entrevistados, enquanto o feminino compreende $30 \%$. Dentre os produtores de Crato, tem-se $75 \%$ do gênero masculino e $25 \%$ feminino. Em Barbalha, a situação se inverte, apresentando a maioria de gênero feminino, com $60 \%$ dos casos, e $40 \%$ do gênero masculino.

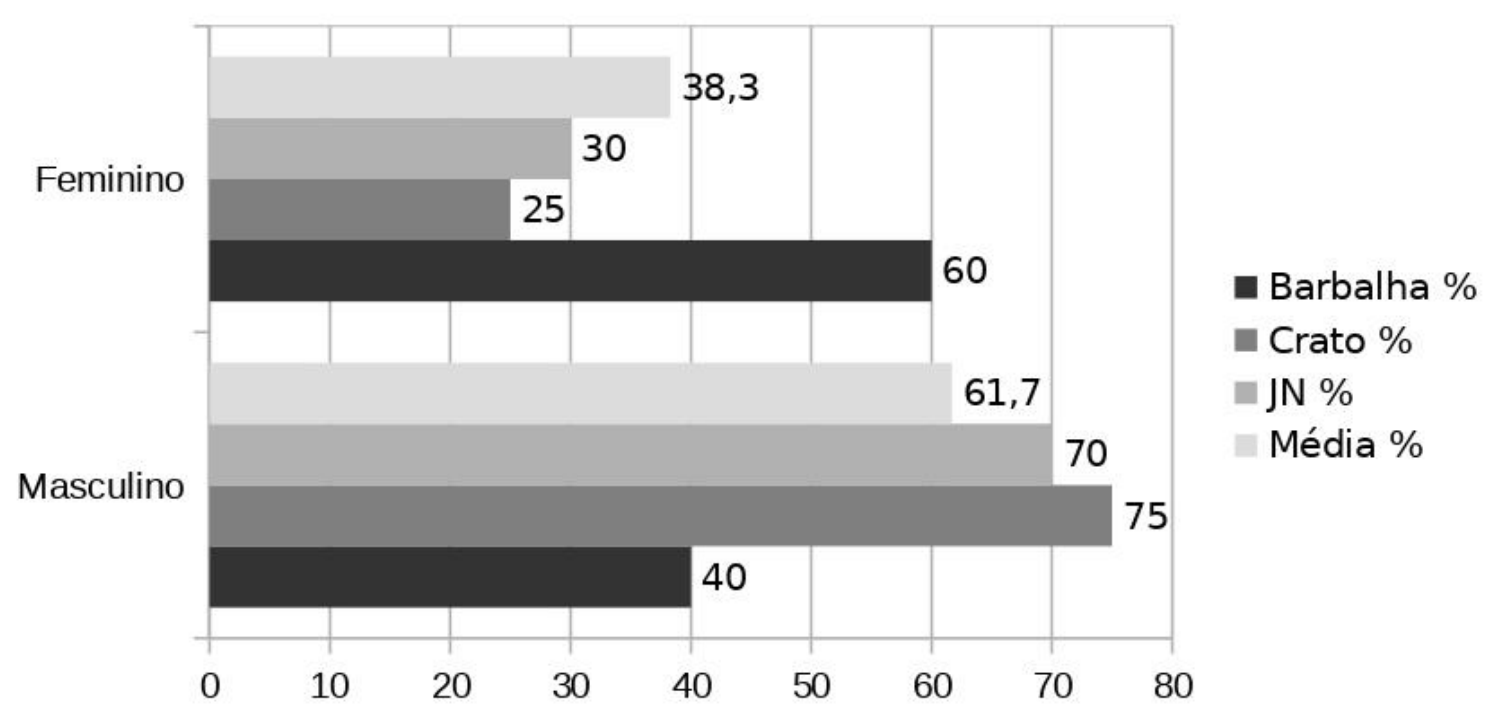

Figura 2. Gênero dos entrevistados. Fonte: Pesquisa aplicada (2020).

Estes resultados encontram alinhamento com os achados da $7^{a}$ Pesquisa de Hábitos do Produtor Rural da Associação Brasileira de Marketing Rural \& Agronegócio ABMRA, desenvolvida em parceria com a Informa Economics IEG | FNP (ABMRA, 2017). O estudo envolveu a participação de 2.835 produtores rurais, de todas as regiões e as principais atividades produtivas brasileiras. Os dados apontam que as mulheres representaram $31 \%$ dos produtores. Dados da Pesquisa Nacional por Amostra de Domicílios Contínua (PNAD Contínua), realizada pelo IBGE, mostram, ainda, uma tímida participação da mulher nas atividades rurais. No primeiro trimestre de 2018, as mulheres representavam $15,38 \%$ dos produtores rurais brasileiros (DATASEBRAE, 2018).

Araújo et al. (2016) observaram, em estudo realizado no município de lguatu, CE, que dentre os entrevistados, apenas 7,7\% eram do gênero feminino. Bracht e Werlang (2015), em pesquisa realizada em Santa Catarina, com o objetivo identificar as competências empreendedoras entre os produtores rurais, também identificaram a 
PERFIL AGROSSOCIOECONÔMICO DE PRODUTORES RURAIS NA REGIÃO METROPOLITANA DO CARIRI CEARENSE

maioria dos produtores como sendo gênero masculino (68\%), enquanto $32 \%$ eram do gênero feminino. A baixa atuação da mulher na agricultura pode ser reflexo das desigualdades de gênero, em que as mulheres, em geral, historicamente ocupam atividades secundárias na produção agrícola, com subordinação em relação ao homem, o que acarreta ausência de expectativas profissionais, desmotivando para a permanência no campo (BRUMER, 2004).

A respeito da idade dos entrevistados, na Figura 3, destaca-se que a maioria dos produtores dos três municípios analisados estão compreendidos na faixa etária de 46 a 65 anos, correspondendo a 48,3\% da média das idades dos inqueridos, $60 \%$ dos casos no município de Juazeiro do Norte, $45 \%$ em Crato e $40 \%$ em Barbalha. Os produtores mais jovens, com idade de até 25 anos são minoria dentre os entrevistados.

Neste quesito, os dados da PNAD Contínua, que se referem ao primeiro trimestre de 2018, corroboram com as informações apresentadas nesta pesquisa, sinalizando que a maioria dos produtores rurais brasileiros possui entre 45 e 65 anos de idade, sendo 26,3\% com idade entre 45 e 55; e 20,5\% com idade entre 55 e 65 anos. Com relação aos produtores com idade de até 25 anos, a PNAD demonstra serem minoria, correspondendo a $6,7 \%$ do total (DATASEBRAE, 2018).

Bracht e Werlang (2015) identificaram a faixa etária predominante de produtores com idade entre 31 e 50 anos, correspondendo a 57\% da amostra. Araújo et al. (2016), por sua vez, observaram maior incidência de entrevistados com idade 41 e 60 anos $(46,15 \%)$.

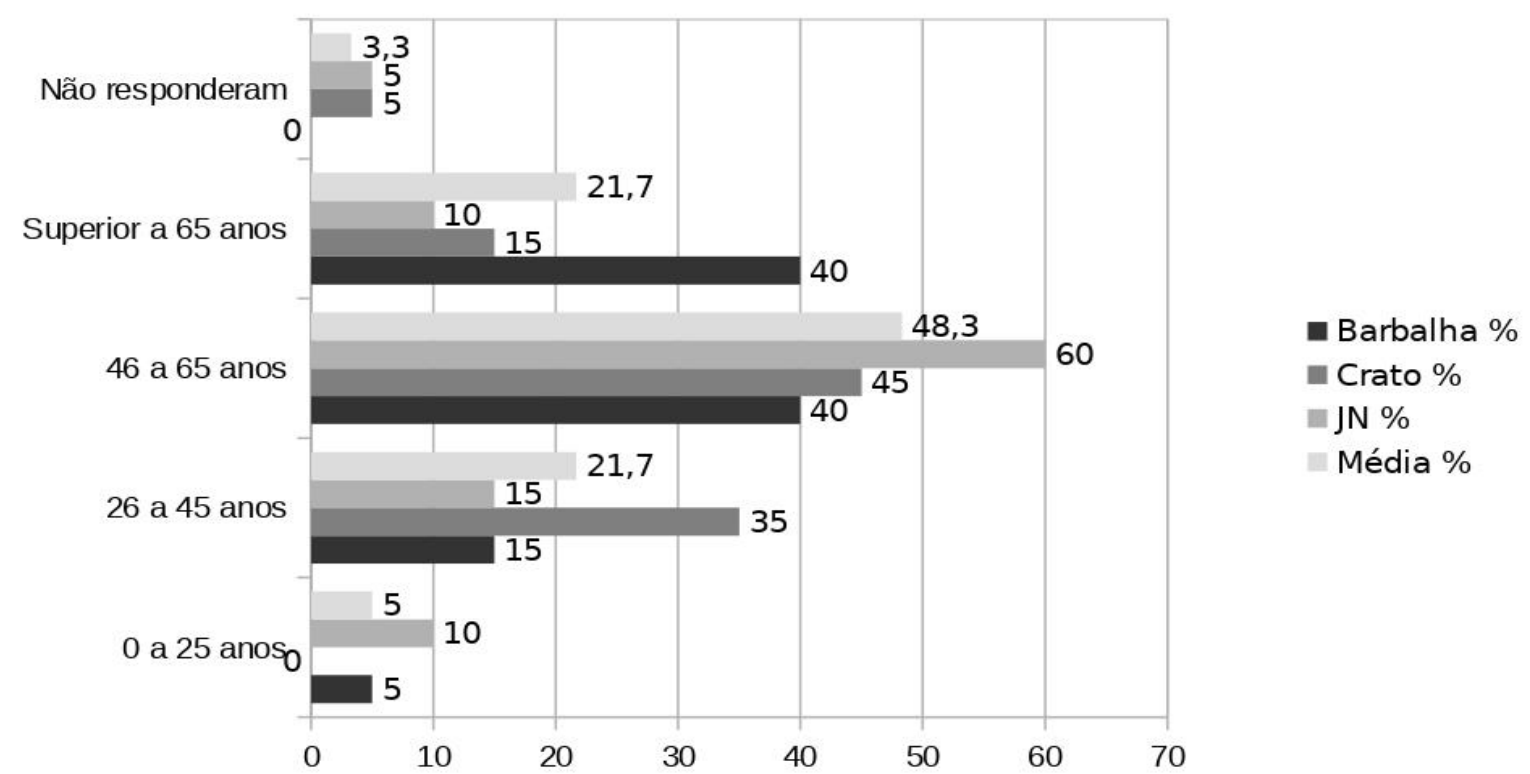

Figura 3. Idade dos entrevistados. Fonte: Pesquisa aplicada (2020).

Com relação à escolaridade dos entrevistados (Figura 4), identificou-se que 46,7\% dos produtores rurais na região Crajubar, para a amostra em análise, em média 
PERFIL AGROSSOCIOECONÔMICO DE PRODUTORES RURAIS NA REGIÃO METROPOLITANA DO CARIRI CEARENSE

possuem apenas o ensino fundamental. Os não escolarizados e detentores do ensino fundamental correspondem a cerca de $70 \%$ dos casos, enquanto $28,3 \%$ apresentam ensino médio. Nenhum dos declarantes afirmou possuir curso de nível técnico ou superior. Apenas 1,7\% afirmaram possuir pós-graduação, nível lato sensu.

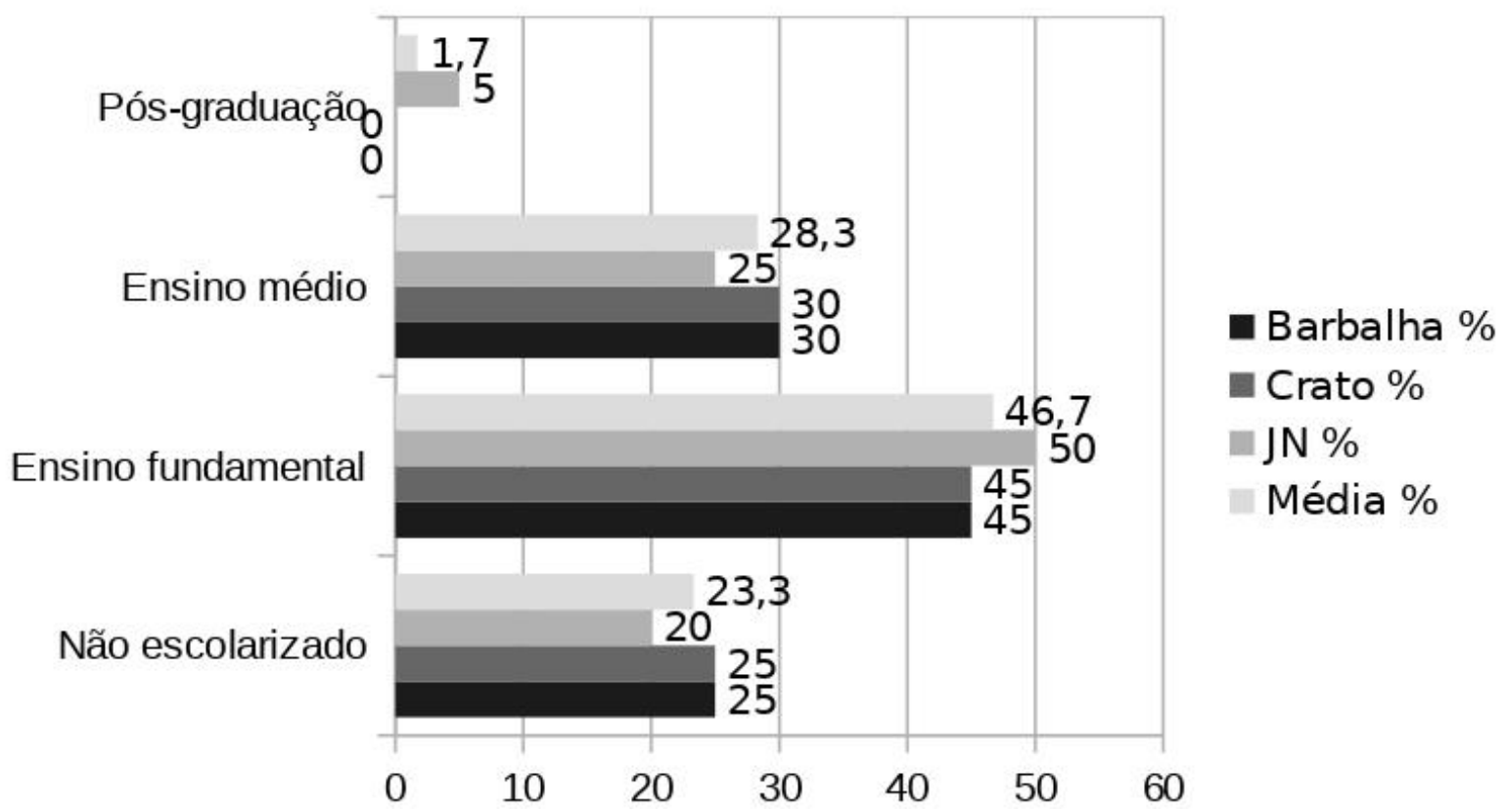

Figura 4. Nível de escolaridade. Fonte: Pesquisa aplicada (2020).

Dentre os municípios analisados, destaca-se que o nível de escolaridade predominante é o ensino fundamental, apresentando percentuais de $45 \%$, $45 \%$ e $50 \%$ para os municípios de Barbalha, Crato e Juazeiro do Norte, respectivamente. Em todos os municípios, para a amostra de estudo, os produtores não escolarizados e com nível fundamental somam $70 \%$ dos entrevistados.

O baixo nível de escolaridade é uma realidade do produtor brasileiro, segundo apontam os dados da PNAD Contínua, em que se constata a predominância de aproximadamente $70 \%$ dos produtores com o ensino fundamental incompleto, $13 \%$ com ensino fundamental completo, $15 \%$ com ensino médio e $2 \%$ com ensino superior (DATASEBRAE, 2018).

Sobre o estado civil dos entrevistados, constatou-se uma média para a região de $76,7 \%$ entrevistados casados ou em união estável, enquanto $21,7 \%$ são solteiros e $1,6 \%$ viúvos. No município de Crato, $85 \%$ dos entrevistados afirmaram ser casados ou viver em união estável, enquanto Barbalha e Juazeiro do Norte apresentaram $75 \%$ e $70 \%$, respectivamente. Estes resultados guardam similaridade com os obtidos por Batista et al. (2015), em Ubá, MG, em que constatando que $87,9 \%$ dos entrevistados eram casados e 6,9\% solteiros. Na pesquisa de Araújo e Feitosa (2016), observando-se o estado civil dos entrevistados, identificaram que 61,54\% eram casados, $30,77 \%$ e solteiros e apenas $7,69 \%$ viúvos. 
PERFIL AGROSSOCIOECONÔMICO DE PRODUTORES RURAIS NA REGIÃO METROPOLITANA DO CARIRI CEARENSE

Quanto à composição familiar dos entrevistados, que corresponde à informação de quantas pessoas moram na residência (Figura 5), incluindo o respondente, registrouse que $75 \%$ dos produtores de Barbalha, $90 \%$ de Crato e $65 \%$ de Juazeiro do Norte têm de 1 a 5 pessoas na residência.

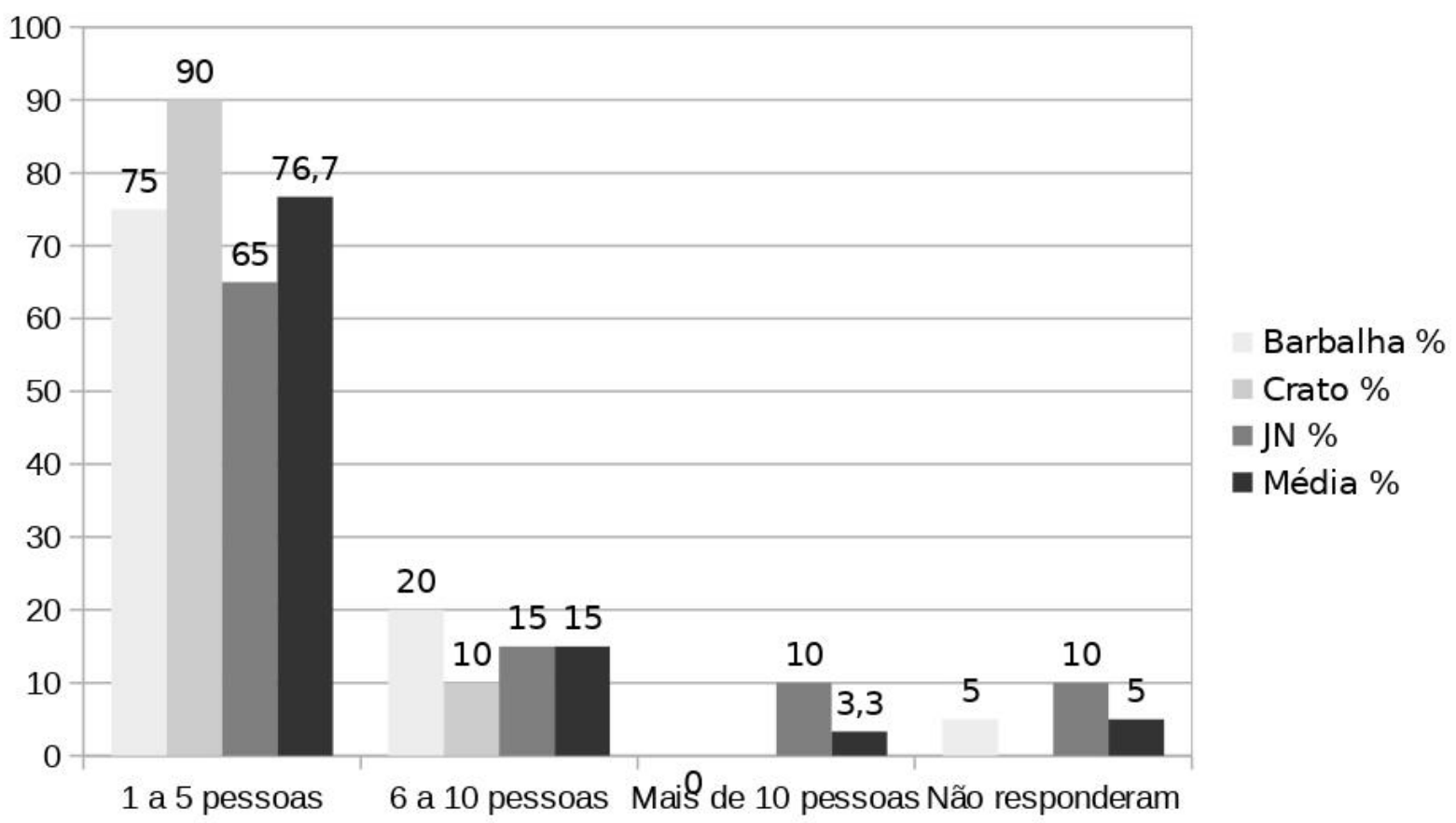

Figura 5. Composição familiar. Fonte: Pesquisa aplicada (2020).

Com isso, identificou-se que as famílias na região, com uma média de 76,7\%, possuem um núcleo familiar reduzido, que pode ser justificado pelo fato da permanência dos produtores detentores de mais idade, enquanto os mais jovens saem do campo em busca de estudos e profissionalização.

Sobre a situação da propriedade rural, destaca-se, inicialmente, que alguns respondentes informaram possuir, concomitantemente, terras arrendadas para desenvolvimento das atividades produtivas, ainda que sejam possuidores de propriedade com escritura ou vivam em área familiar. Este fato decorre da área das propriedades serem insuficientes, em sua maioria tratam-se de minifúndios. Deste modo, constatou-se que uma média de $45 \%$ dos entrevistados da região Crajubar possuem escritura da terra, enquanto $25 \%$ admitem não possuir, $26,27 \%$ vivem em terras familiares ou cedidas, $6,7 \%$ em terras arrendadas e 1,7\% não informaram a condição da propriedade.

Em Barbalha, $40 \%$ possuem escritura, $20 \%$ detêm apenas o termo de posse, em $30 \%$ dos casos a terra é familiar ou cedida e 10\% detêm terras arrendadas. Em Juazeiro do Norte, $50 \%$ têm escritura da terra, $15 \%$ não possuem, em $40 \%$ dos casos a terra é familiar ou cedida e $5 \%$ detêm terras arrendadas. No caso de Crato, $45 \%$ dos 
PERFIL AGROSSOCIOECONÔMICO DE PRODUTORES RURAIS NA REGIÃO METROPOLITANA DO CARIRI CEARENSE

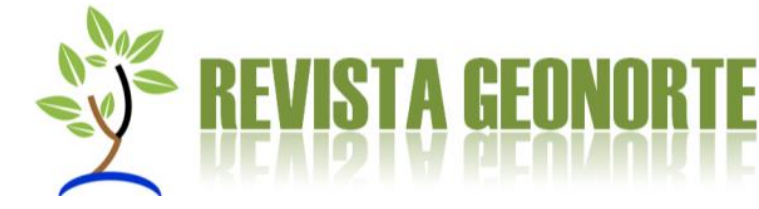

produtores têm escritura, $40 \%$ não possuem, $10 \%$ vivem em propriedade familiar ou cedida e $15 \%$ têm áreas arrendadas.

Destaca-se a importância do Programa de Regularização Fundiária, no Estado do Ceará, que beneficia diretamente a agricultura familiar do Estado ao oportunizar o acesso ao título de posse rural ao produtor. De acordo com dados do Instituto do Desenvolvimento Agrário do Ceará (Idace), O programa já contemplou 136 municípios cearenses e entregou mais de 93 mil títulos de terra. O Programa Cadastro de Terras e Regularização Fundiária é fruto de uma parceria entre o Governo Federal e o Governo do Ceará. O Estado atua por meio da Secretaria do Desenvolvimento Agrário (SDA) e do Idace; e o Governo Federal, com a participação do Instituto Nacional de Colonização e Reforma Agrária (Incra) e da Secretaria Nacional de Assuntos Fundiários do Ministério da Agricultura (CEARÁ, 2019).

Cumpre ressaltar que, de acordo com Coutinho e Rodrigues (2015), a reconfiguração da estrutura fundiária permite ao homem do campo o acesso e uso da terra de maneira mais democrática e igualitária, passando a ser um direito que oportuniza condições de vida e trabalho mais dignas.

Referente ao Cadastro Ambiental Rural - CAR, 70\% dos produtores entrevistados na região afirmaram possuir o CAR, enquanto $25 \%$ não possuem e $5 \%$ não souberam responder. Em Barbalha, chega a $80 \%$ o total de entrevistados cadastrados no CAR, seguida por Crato e Juazeiro do Norte, que apresentaram 70\% e 60\% de produtores cadastrados, respectivamente. Como é possível observar, a menor adesão observada foi em Juazeiro do Norte. Dentre os produtores que responderam negativamente ao questionamento sobre o registro, identificou-se resistência relacionada à falta de conhecimento e desconfiança a respeito da finalidade, objetivos e vantagens em realizar o cadastro.

Quando questionados acerca dos serviços disponíveis nas propriedades, os entrevistados informaram que dispõem de banheiro em casa, em média 93,3\% dos produtores entrevistados na região, com fossa séptica ( $80 \%) ; 8,3 \%$ dos entrevistados afirmaram possuir banheiro no quintal. Além disso, as propriedades possuem energia elétrica $(98,3 \%)$ e água encanada (83,3\%). Porém, o esgoto domiciliar é despejado a céu aberto, segundo 78,3\% dos entrevistados; e, em apenas $8,3 \%$ dos casos, admitiuse possuir rede de esgoto na propriedade.

Com relação à renda familiar, incluindo além da atividade rural, os benefícios previdenciários, rendimentos de outras atividades de trabalho informal e bolsa família (Figura 6), constatou-se a predominância de produtores com renda entre 1 e 4 salários-mínimos, com percentuais de 55\% na média da região, destacando-se Crato e Juazeiro do Norte, em que $60 \%$ dos entrevistados, em ambos municípios, declararam a referida faixa de rendimentos. No município de Barbalha, contudo, $50 \%$ dos entrevistados apresentaram renda de até 1 salário-mínimo.

Observa-se um baixo nível de renda auferido pelos produtores rurais, no desempenho exclusivo da atividade agrícola (Figura 7), com destaque para o município de Barbalha, em que 95\% dos respondentes declararam possuir renda de até 1 (um) 
PERFIL AGROSSOCIOECONÔMICO DE PRODUTORES RURAIS NA REGIÃO METROPOLITANA DO CARIRI CEARENSE

salário-mínimo. A média para a região, de acordo com a amostra analisada, é de $73,3 \%$ dos entrevistados com renda de até 1 salário-mínimo.

Os resultados do presente estudo, que apontam para baixos níveis de rendimentos auferidos na atividade rural, acompanham a tendência nacional. De acordo com dados da PNAD Contínua, no primeiro trimestre de 2018, 82,6\% dos produtores rurais brasileiros recebiam até 2 (dois) salários-mínimos mensais, $12 \%$ auferiam renda entre 2 e 5 salários e 5\% recebiam mais de 5 salários-mínimos (DATASEBRAE, 2018).

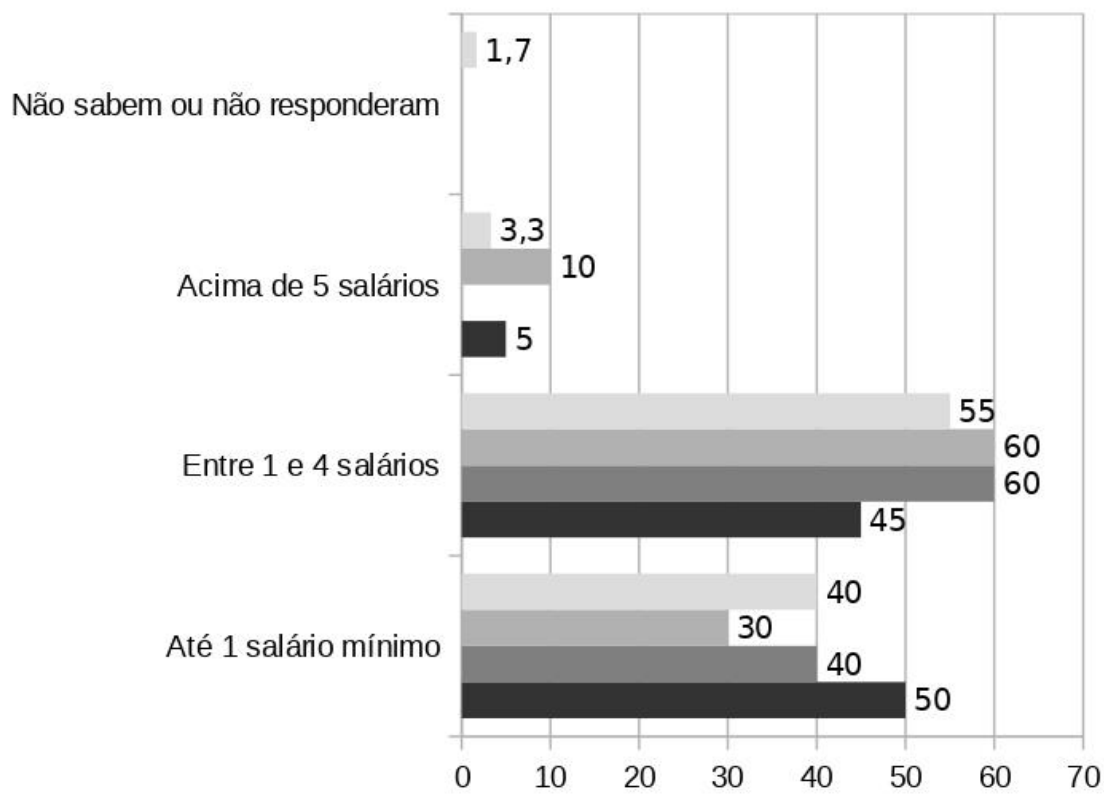

\author{
Barbalha \% \\ Crato \% \\ a JN \% \\ Média \%
}

Figura 6. Renda familiar total. Fonte: Pesquisa aplicada (2020).

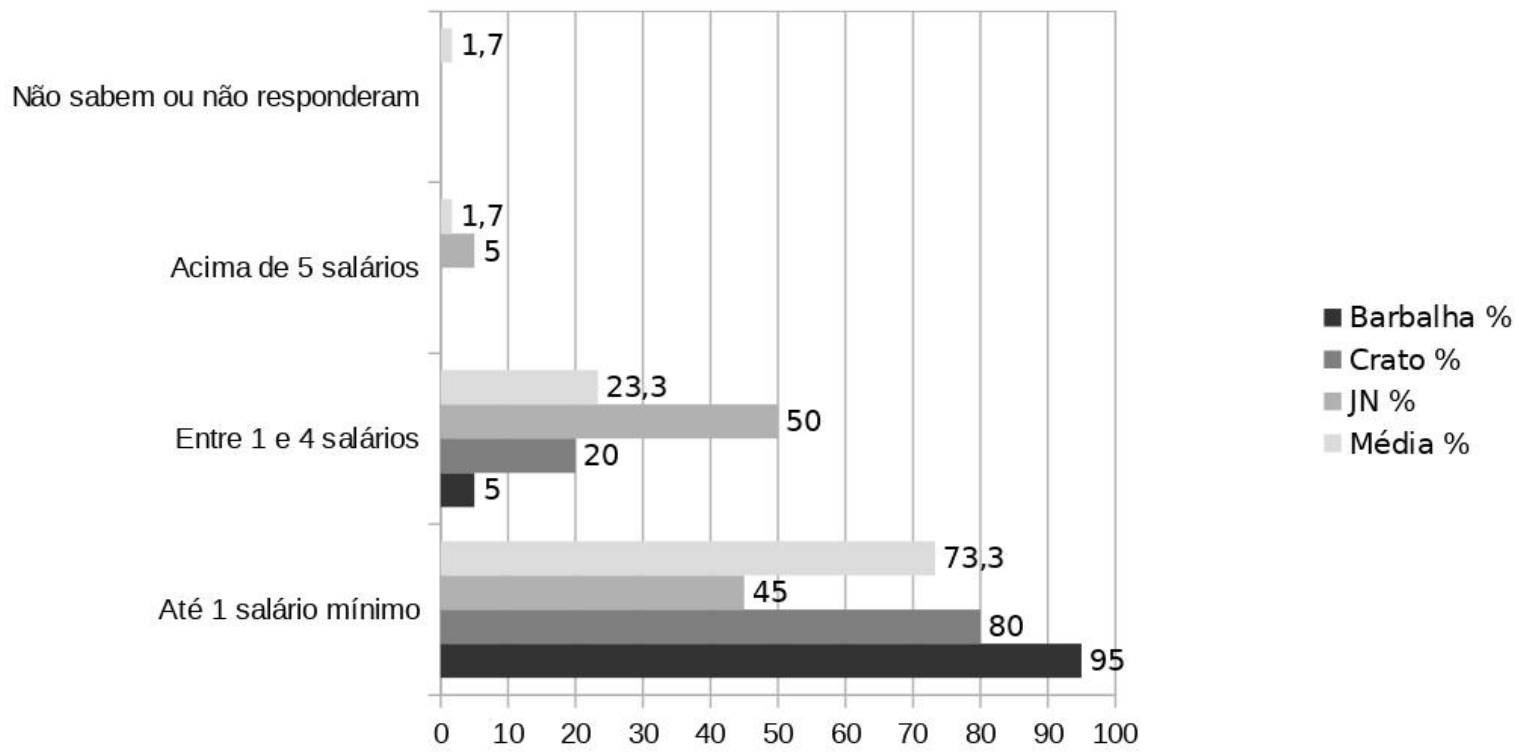

Figura 7. Renda exclusiva com a atividade rural. Fonte: Pesquisa aplicada (2020). 
PERFIL AGROSSOCIOECONÔMICO DE PRODUTORES RURAIS NA REGIÃO METROPOLITANA DO CARIRI CEARENSE

Do mesmo modo, na pesquisa desenvolvida por Araújo e Feitosa (2016), no município de Iguatu, CE, evidenciou-se um baixo nível de rendimentos dos produtores rurais. Foi verificada uma renda familiar entre 2 a 4 salários-mínimos para 84,62\% dos entrevistados. A referida renda envolve outras atividades de trabalho informal ou ainda benefícios sociais do Governo. A renda oriunda apenas da atividade rural foi de até 1 salário mínimo para $76,92 \%$ dos entrevistados.

Ressalta-se que em propriedades rurais pequenas, com reduzido número de indivíduos atuando na atividade rural, com produção prioritária para a subsistência é fator que serve para explicar os baixos níveis de rendimentos mensais da atividade (DATASEBRAE, 2018).

Com relação ao tamanho da propriedade rural (Figura 8), bem como sua área destinada à exploração, evidenciou-se a predominância de imóveis com área inferior a 5 (cinco) hectares, caracterizando-se como pequenas propriedades rurais. Em alguns casos, os entrevistados relataram que em função da área ser pequena não possuíam acesso a programas governamentais, como por exemplo Garantia Safra, que exige uma área de terra superior a 0,6 ha.

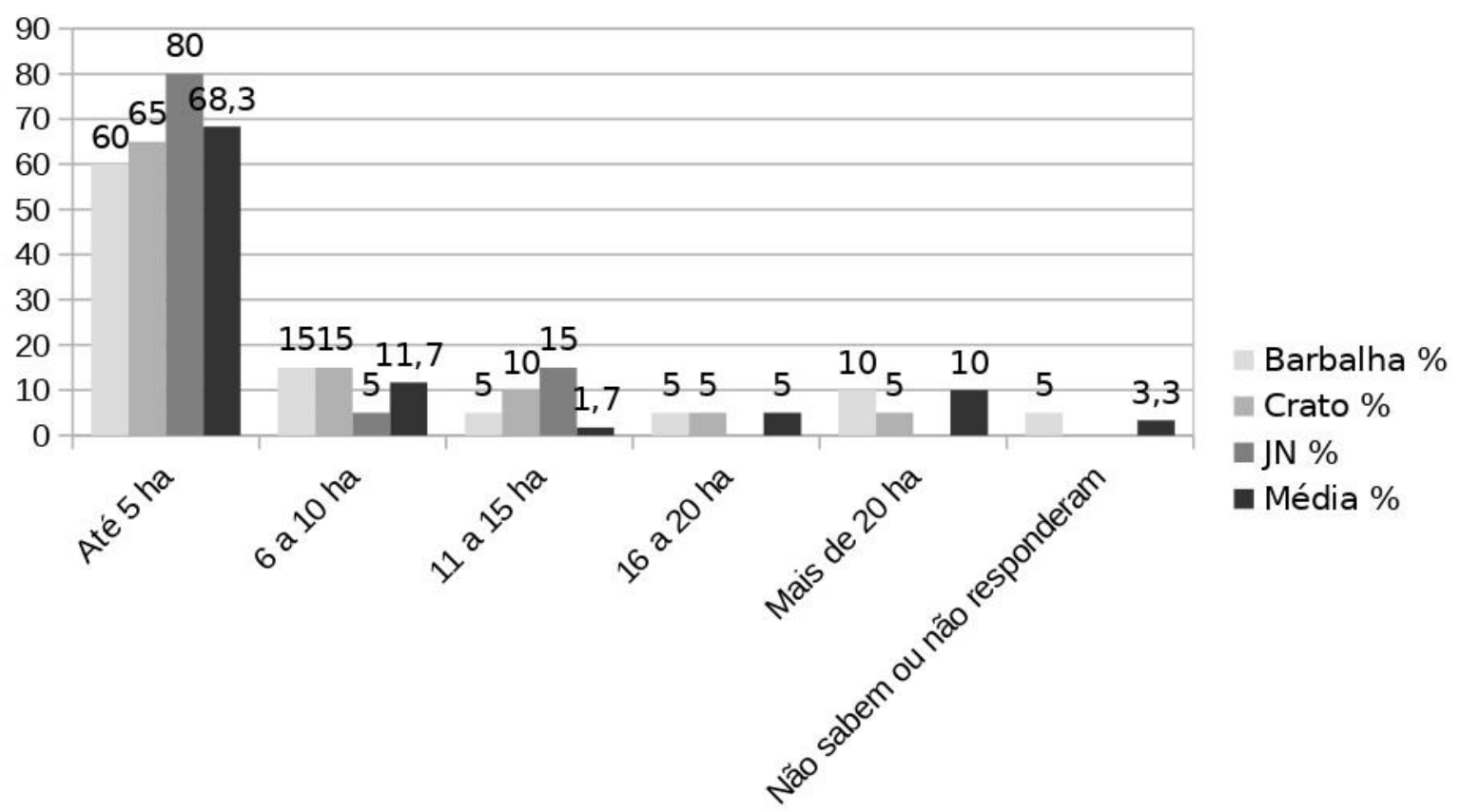

Figura 8. Tamanho das propriedades. Fonte: Pesquisa aplicada (2020).

Segundo Marques (2015), a existência de minifúndios decorre, especialmente, das divisões de sucessões e heranças, em famílias numerosas. Contudo, estas áreas são insuficientes para corroborar com o progresso econômico e, por sua vez, atender à função social da terra, pois ainda que trabalhadas por uma família, são insuficientes para propiciar subsistência e o progresso social do grupo.

A respeito dos recursos e subsídios do governo, tais como Garantia Safra e Pronaf, um percentual médio de $51,7 \%$ dos produtores da região afirmaram não receber 
PERFIL AGROSSOCIOECONÔMICO DE PRODUTORES RURAIS NA REGIÃO METROPOLITANA DO CARIRI CEARENSE

nenhum recurso, 25\% declararam receber Pronaf, 21,7\%, Seguro Safra, e 1,6\% afirmaram ter acesso a outros tipos de recursos. Dentre os municípios analisados, Barbalha e Juazeiro do Norte destacaram-se com $65 \%$ dos entrevistados que não recebem nenhum recurso e o motivo principal elencado pelo grupo é o tamanho insuficiente da área do imóvel.

Em Barbalha, 15\% afirmaram receber o Seguro Safra e 20\% o Pronaf. Em Juazeiro do Norte, $20 \%$ declararam receber o Seguro Safra e 15\% o Pronaf. Em Crato, 25\% não recebem recursos/benefícios, 30\% dos entrevistados declararam receber Seguro Safra, $40 \%$ têm Pronaf e 5\% recebem outros tipos de subsídios.

Relativamente à assistência técnica recebida pelos produtores, evidenciou-se uma média de $50 \%$ dos produtores da região que recebem assistência da Ematerce, sendo $40 \%$ em Barbalha, $50 \%$ em Crato e $60 \%$ em Juazeiro do Norte. Porém, os relatos apontam para um insuficiente acompanhamento, tendo em vista o pequeno número de técnicos disponíveis. Em 43,3\% da média da região, os produtores afirmam não recebem nenhuma assistência. Esta é a realidade para $45 \%$ dos produtores de Barbalha e Crato; bem como para $40 \%$ dos produtores de Juazeiro do Norte. Apenas no município de Barbalha, $10 \%$ dos produtores relataram que contratam assistência particular. Em Crato e Barbalha, 5\% não responderam se há assistência técnica.

Dentre as atividades desenvolvidas na propriedade rural, destaca-se a avicultura, com média de $81,7 \%$ dos casos, de acordo com os entrevistados; seguida do cultivo de milho e feijão, ambos em $80 \%$ das propriedades da região, considerando a amostra deste estudo. Ademais, foram ressaltadas a fruticultura $(58,3 \%)$, a suinocultura $(53,3 \%)$ e o cultivo de hortaliças $(43,3 \%)$. A bovinocultura e a caprino/ovinocultura apresentaram resultados tímidos, com 16,7\% e 10\%, respectivamente, o que pode ser justificado pelo tamanho das áreas das propriedades, que são predominantemente minifúndios, logo insuficientes para a criação destes animais. Destaca-se que a avicultura está presente como uma atividade sobretudo de subsistência, para o consumo familiar.

O destino da produção realizada nas propriedades em questão refere-se, principalmente ao consumo próprio familiar, que se apresenta em 91,7\% da média da região, sendo 95\% dos casos de Barbalha e Crato, enquanto Juazeiro do Norte conta com $85 \%$ dos casos. O excedente é comercializado em feiras locais, responderam $60 \%$ dos produtores de Barbalha, $45 \%$ de Crato e $50 \%$ de Juazeiro do Norte. Destacase, ainda, a entrega da produção, em $30 \%$ dos entrevistados, para os programas de alimentação escolar quais sejam: Programa de Aquisição de Alimentos (PAA), instituído em 2003, e o Programa Nacional de Alimentação Escolar (PNAE), Lei 11.947/2009.

Além disso, $25 \%$ dos produtores também informaram que comercializam alguns produtos na sede da propriedade, sendo $10 \%$ dos produtores de Barbalha, $25 \%$ dos produtores de Crato e $40 \%$ dos produtores de Juazeiro do Norte. Apenas os produtores $(13,3 \%)$ manifestaram a entrega de produtores para cooperativa/associação. 
PERFIL AGROSSOCIOECONÔMICO DE PRODUTORES RURAIS NA REGIÃO METROPOLITANA DO CARIRI CEARENSE

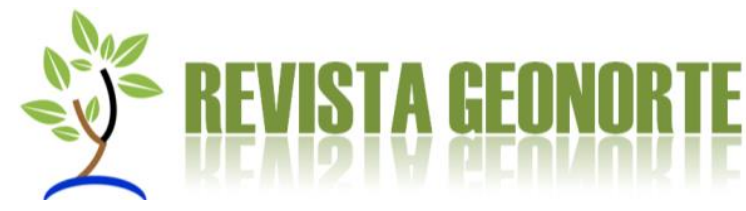

\section{CONSIDERAÇÕES FINAIS}

Este artigo apresenta resultados de um levantamento realizado na Região Metropolitana do Cariri Cearense, com uma amostra de 60 produtores rurais, dos municípios de Crato, Juazeiro do Norte e Barbalha. De acordo com a pesquisa aplicada, foi possível observar que o perfil do produtor rural na Região Metropolitana do Cariri apresenta predominância do gênero masculino (61,7\%), sendo a maioria $(48,3 \%)$ compreendidos na faixa etária de 46 a 65 anos, possuindo por nível de escolaridade o ensino fundamental (46,6\%), alcançando $70 \%$ dos entrevistados, quando somados os produtores não escolarizados e de nível fundamental. Ademais, constatou-se uma média de $76,7 \%$ entrevistados casados ou em união estável, apresentando de 1 a 5 pessoas residentes no domicílio.

A respeito da renda familiar, incluindo outras fontes, além da atividade rural, constatouse a predominância de produtores com renda entre 1 e 4 salários-mínimos (55\%), enquanto a renda declarada como exclusiva da atividade agrícola foi de até 1 (um) salário-mínimo. Evidenciou-se, ainda, dentre os produtores consultados, a predominância de imóveis com área inferior a 5 (cinco) hectares, caracterizando-se como pequenas propriedades rurais.

Observando-se as atividades desenvolvidas na propriedade rural, destacam-se: a avicultura, com média de $81,7 \%$ dos casos, de acordo com os entrevistados; e, o cultivo de milho e feijão, ambos em $80 \%$ das propriedades da região. Quanto ao destino da produção, os produtores indicaram principalmente o consumo próprio familiar $(91,7 \%)$, sendo o excedente comercializado em feiras locais $(51,7 \%)$. Destaca-se, ainda, a entrega da produção para os programas de alimentação escolar (30\%) e a comercialização, em $25 \%$ dos casos, na sede da propriedade.

As informações expostas caracterizam o setor agrícola da região composto por pequenas propriedades, baixa escolaridade dos produtores e reduzido nível de renda, proveniente exclusivamente da agricultura. Ademais, a produção reflete um modelo de agricultura de subsistência, marcado pela expressiva maioria de produtores que destinam sua produção ao consumo familiar. Evidenciou-se, contudo, a participação em programas de alimentação escolar e a comercialização na sede da propriedade. Dentre as estratégias de comercialização adotadas, destaca-se o papel da feira livre, como um eficiente canal de comercialização viável para pequenos agricultores familiares. Cumpre ressaltar a importância do fortalecimento do setor, por meio da criação de políticas governamentais de apoio e garantia da produção e comercialização dos produtos agrícolas na região. 
PERFIL AGROSSOCIOECONÔMICO DE PRODUTORES RURAIS NA REGIÃO METROPOLITANA DO CARIRI CEARENSE

\section{REFERÊNCIAS}

ABMRA - Associação Brasileira de Marketing Rural \& Agronegócio. 7ª Pesquisa de hábitos do produtor Rural, jun. 2017. Disponível em: http://abmra.org.br/wpcontent/uploads/2017/06/7_EDICAO_PESQUISA HABITOS_DO_PRODUTOR_RU RAL_ABMRA_JUNHO_17.pdf. Acesso em: 20 out. 2019.

ARAÚJO, F. M. L.; FEITOSA, A.K; ANTAO, M.N. Perfil agrossocioeconômico de produtores rurais nos sítios do Cardoso I e II no município de Iguatu-CE. Rev. Educação Ambiental em Ação, v. XV, n. 57, Set./Nov, 2016.

BARDIN, L. Análise de conteúdo. São Paulo: Edições 70, 2011.

BATISTA, L. M. G. et al. Perfil sócio demográfico e das atividades agrícolas de manejo e produção de agricultores familiares inscritos no programa de aquisição de alimentos - PAA, do Município de Ubá-MG. Revista Brasileira de Agropecuária Sustentável (RBAS), v.5, n.2, p. 9-18, dez. 2015.

BRACHT, D. E; WERLANG, N. B. Competências empreendedoras: uma investigação com produtores rurais catarinenses. Revista de Empreendedorismo e Gestão de Pequenas Empresas, v. 4, n. 1, 2015.

BRUMER, A. Gênero e agricultura: a situação da mulher na agricultura do Rio Grande do Sul. Estudos Feministas, Florianópolis, v.12, p. 360, janeiro-abril/2004.

CEARÁ. Secretaria de Desenvolvimento Agrário. Programa de Regularização Fundiária do Ceará é modelo para o Brasil, 31 maio 2019. Disponível em: https://www.ceara.gov.br/2019/05/31/programa-de-regularizacao-fundiaria-do-cearae-modelo-para-o-brasil3/ Acesso em: 09 dez. 2019.

CEARÁ. Secretaria das Cidades. Região Metropolitana do Cariri, [on-line]. Disponível em: https://www.cidades.ce.gov.br/regiao-metropolitana-do-cariri/ Acesso em: 02 maio 2020.

COUTINHO, J.L.R.; RODRIGUES, D.C.B. Estrutura fundiária e cidadania: a questão da terra no brasil. In: Anais da VII Jornada Internacional de Políticas Públicas, Universidade Federal do Maranhão, São Luis, 25 a 28 de ....de 2015.

DATASEBRAE. Perfil do produtor rural, 2018. Disponível em: https://datasebrae.com.br/perfil-do-produtor-rural/. Acesso em: 20 out. 2019.

IPECE - Instituto de Pesquisa e Estratégia Econômica do Ceará. Panorama socioeconômico das regiões metropolitanas cearenses. Fortaleza: IPECE, 2018. 
PERFIL AGROSSOCIOECONÔMICO DE PRODUTORES RURAIS NA REGIÃO METROPOLITANA DO CARIRI CEARENSE

MANGABEIRA, J. A. de C.; MIRANDA, E. E. de; GOMES, E. G. Perfil Agrossocioeconômico dos Produtores Rurais de Machadinho d'Oeste (RO) em 2002. Campinas: Embrapa Monitoramento por Satélite, 2005.

MARQUES, B. F. Direito agrário brasileiro. 11. Ed. Rev. E ampl. São Paulo: Atlas, 2015.

MIRANDA, E. E. Perfil do produtor e manejo de pragas na Microrregião Dourados, MS. Campinas: Embrapa Agropecuária Oeste, 2009.

MANGABEIRA, J. A. de C.; GREGO, C. R. Desmistificação da terra: o perfil em 2005 dos produtores rurais de Machadinho d'Oeste (RO), 23 anos depois. Campinas: Embrapa Monitoramento por Satélite, 2007.

NUNES, E. M. et al. Dinamização Econômica e Agricultura Familiar: limites e desafios do apoio a Projetos de Infraestrutura (Proinf) em territórios rurais do Nordeste. RESR, Piracicaba-SP, v. 53, n. 3, p. 529-554, nov. 2015

PAIS, H. L. R. Região Metropolitana do Cariri - R.M.C : uma análise a partir da política de desenvolvimento territorial. Dissertação (mestrado). Mestrado Profissional em Avaliação de Políticas Públicas, Universidade Federal do Ceará, Fortaleza, 2014.

QUEIROZ, I.S. Região metropolitana do cariri cearense, a metrópole fora do eixo. Mercator, Fortaleza, v. 13, n. 3, p. 93-104, set./dez. 2014

RICHETTI, A.; MORAES, G.C. Perfil do produtor e manejo de pragas na Microrregião Dourados, MS, Embrapa Agropecuária Oeste, 2009. 